\title{
Sexual Risk Behaviours among People Living with HIV and Implications for Control in the North West Region of Cameroon
}

\author{
Tebit Emmanuel Kwenti1,2,3*, Dickson Shey Nsagha ${ }^{4}$, Bita Dizzle Tayong Kwenti ${ }^{3}$, \\ Anna Longdoh Njunda ${ }^{2}$ \\ ${ }^{1}$ Regional Hospital Buea, Buea, Cameroon \\ ${ }^{2}$ Department of Medical Laboratory Sciences, Faculty of Health Sciences, University of Buea, Buea, Cameroon \\ ${ }^{3}$ Department of Microbiology and Parasitology, Faculty of Science, University of Buea, Buea, Cameroon \\ ${ }^{4}$ Department of Public Health and Hygiene, University of Buea, Buea, Cameroon \\ Email: ${ }^{*}$ kwentitebit@yahoo.com, ${ }^{*}$ emmakwen@gmail.com
}

Received 17 March 2014; revised 17 April 2014; accepted 27 April 2014

Copyright (C) 2014 by authors and Scientific Research Publishing Inc.

This work is licensed under the Creative Commons Attribution International License (CC BY). http://creativecommons.org/licenses/by/4.0/

(c) (i) Open Access

\section{Abstract}

In Cameroon, despite extensive control efforts against HIV/AIDS, the number of new HIV infections is still on the rise. The factors contributing to this are not clearly understood. We hypothesized that it may lie on people living with HIV (PLHIV). In a case-control descriptive study, we studied the characteristics and sexual risky behaviour of PLHIV in the North West Region of Cameroon which has the highest HIV prevalence. Participants were screened for HIV and a structured questionnaire was used in data collection. An equivalent number (350) of PLHIV and controls who did not differ with respect to age and sex participated. Relative to the control, PLHIV were generally less educated $(P<0.001)$, poorer and less privileged $(P<0.001)$ with no stable source of income. Among participants that were once married, a greater proportion of PLHIV were divorced $(O R=5.23, P=0.007)$, and widows $(O R=2.73, P=0.001)$. Among participants that were single, $a$ relatively greater proportion of PLHIV practiced multi-partner sex $(O R=4.55, P<0.001)$. History of STDs was higher in PLHIV than the control $(O R=1.88, P=0.001)$. Out of 350 PLHIV, $280(80 \%)$ admitted to having had sexual intercourse after being diagnosed of which only 127 (41.78\%) admitted to using condoms and $132(47.14 \%)$ admitted to concealing their HIV status from their sexual partner(s). These findings have implications in HIV control programs which should target the poor and the less educated, as well as the sexual behaviour of PLHIV, so as to reverse the current rising trend of new infections in the country.

\footnotetext{
${ }^{*}$ Corresponding author.
} 


\section{Keywords}

\section{HIV/AIDS, STDs, Risk Factors, HIV Control, North West Region, Cameroon}

\section{Introduction}

HIV is one of the most prevalent and debilitating sexually transmitted diseases with approximately 35.3 million people living with the virus globally [1]. The disease is generally regarded as a pandemic [2]. Sub-Saharan Africa has the highest regional prevalence with an estimated 23.5 million people living with HIV [3]. Cameroon had an HIV prevalence of 5.5\% which was among the highest in West and Central Africa [4]. Although the prevalence has been observed to be declining over the past decade, the number of people living with the disease has been on the rise from 416,000 in 2000 to 560,000 in 2010, with a projected increase of up to 726,000 in 2020 [5]. Within the country, the disease is not evenly distributed with the highest prevalence reported in the North West Region (8.7\%), East (8.6\%), Yaoundé (8.3\%) and the South West (8\%) while the lowest prevalence has been reported in North (1.7\%) and Extreme North regions (2\%) [5].

Sexual contact is the major mode of transmission of HIV [6]. Other modes include contaminated blood transfusions, hypodermic needles, and modes from mother to child during pregnancy, delivery, or breastfeeding [6]. Risk factors of transmission include those that have to do with sexual behavior such as unprotected sex [7], anal sex [7] [8], presence of other STDs [9], commercial sex workers [10] [11]. Currently there is no cure or vaccine for HIV. Preventing new HIV infections is the most effective way to halt the epidemic. National HIV control programs are greatly hinged on the education of at-risk population through regular sensitization campaigns which focus on promoting responsible sexual behaviour, such as monogamy, a reduction in partners, and correct and consistent condom use; ensuring a safe blood supply, treating STIs, and the organization of regular screening campaigns to ensure people know their HIV status.

Despite all these efforts, the number of people living with the disease is still on the rise in the country, with an estimated 51,315 new infections per year [5]. The contributing factors to these staggering numbers remain to be investigated. We hypothesized that the problem may lie on people living with HIV (PLHIV), which is largely overlooked especially in the North West Region of Cameroon, where the highest prevalence of HIV has been reported [5]. By studying the sexual behaviour of PLHIV in the North West region of Cameroon, we hope to generate data that may be useful in designing HIV control programs in the area.

\section{Materials and Methods}

\subsection{Study Area}

Participants were recruited in Bamenda (coordinates $5^{\circ} 56^{\prime} \mathrm{N} 10^{\circ} 10^{\prime} \mathrm{E}$ the capital of the North West Region of Cameroon (a country situated on the west wing of Central Africa). With a population of over 817,000 people according to the 2012 census [12], it is culturally diverse with people of different ethnic origins converging for business, education and work. As the main regional center, the city has many markets, banks and offices. Common factories in Bamenda include; mil, soap, poultry, fishing, bakeries, printing, wood processing, rice hauling, and two beer brewery depots. The main industries are involved in processing of agricultural products like coffee. Bamenda is also important politically as the seat of the major opposition party, the Social Democratic Front (SDF). Bamenda has a museum in the Mankon Fon's Palace. All these together with the terrain around the city attract lots of people to this city including tourists.

The activities of the inhabitants in Bamenda include those involved in the public service employed by the government as well as the private sector, general business with presence of many mechanic's, panel beater's, iron bender's, automobile sprayer's, welder's, old vehicle spare parts seller's workshops and hair dressing saloons. There are also many carpentry workshops and beer parlours in Bamenda. Pastoral farming in Bamenda consists of cattle, sheep, goat, pig, and chicken rearing which are common, as well as peasant farming which is practiced by most inhabitants.

Study participants were recruited using Mbingo Baptist Hospital (MBH) and Nkwen Baptist Health Center. 


\subsection{Study Design}

This was a case-control descriptive study involving PLHIV as the cases and non HIV-infected individuals as the controls.

\subsection{Study Population}

Males and females of the ages 18 years and above were eligible for the study and were recruited upon provision of their signed informed consent form which was duly explained to them in French, English or the local pidgin language. For individuals who could not read or write or for one reason or the other could not provide their consent, the guardian, caregiver, or next of kin did on their behalf.

Exclusion criteria were individuals below 18 years of age, refusal to give their informed consent and failure to return the study questionnaire.

The study protocol was approved by the Cameroon Baptist Convention Institutional Review Board (CBC IRB) IRB 2011-11.

\subsection{Questionnaire and Sample Collection}

A questionnaire was administered to participants to fill and return in a sealed envelope that was provided. Questionnaires were identified by a coding system, no names were collected. After completion of questionnaire, $4 \mathrm{ml}$ of blood specimen were collected into EDTA test tubes for HIV screening.

\subsection{HIV Screening}

HIV screening was done in accordance with the Cameroon's algorithm of HIV screening [13]. Briefly, a first line rapid test was used and if positive, a second line test was used to confirm the result as well as determine the HIV type. Where the first line test was positive and the second line test was negative, a third line test was brought in. In this study, the first line test used was Determine ${ }^{\mathrm{TM}}$ HIV (Abbott Laboratories, Abbott Park, IL, USA), the second line test was Hexagon (Human Diagnostic, Germany) and the third line test was ImmunoComb® (Orgenics Ltd., Israel).

\subsection{Statistical Analysis}

Data obtained from the questionnaire were keyed into Excel spread sheet and encrypted with a password known only to the Principal Investigator. Statistical analysis were performed using Stata ${ }^{\circledR}$ version 12.1 (StataCorp LP) statistical package and group comparisons were performed using the Student's t-test, Chi-square test and the Fisher exact test. Odd Ratio (OR) was also determined. Statistical significance was set at $\mathrm{P}<0.05$.

\section{Results}

\subsection{Demographic Characteristics of Participants}

In this study, 368 controls were screened of which 18 (4.89\%, 95\% CI: 2.68 - 7.1) were found positive for HIV. In addition to the 18, 332 PLHIV were contacted. At the end of the study, 350 PLHIV and 350 HIV-negative individuals (controls) successfully participated. Among the 350 PLHIV were 207 (73.4\%) females and 93 (26.6\%) males and their ages ranged between 18 and 75 (mean = 39 years). Among the controls were 247 (70\%) females and 105 (30\%) males. The two groups did not differ with respect to sex $(\mathrm{P}=0.80)$ and age $(\mathrm{P}=0.99)$. In PLHIV, the most prevalent HIV strain was type 1 (275, 78\%), followed by type 1 \& 2 (48, 14\%), type 2 (27, 8\%) being the least.

A majority of PLHIV had only primary education 178 (51.15\%) meanwhile for the control a relatively small proportion had only primary education 114 (32.76\%). Relative to the PLHIV, a greater proportion of the controls progressed up to the tertiary level (25.68\% vs. $10.63 \%$, OR $=0.3895 \% \mathrm{CI}$ : $0.16-0.89, \mathrm{P}=0.04)$ (Figure 1). Overall, a highly significant difference was observed between the educational level of PLHIV and the control (P $<0.001)$.

Relative to the control, a majority of PLHIV in this study were farmers (26.36\% vs. $10.57 \%$, OR = 3.73, $95 \%$ CI: 1.54 - 9.05, P = 0.005), self-employed (36\% vs. 27.43\%, OR = 1.97, 95\% CI: $0.85-4.57, \mathrm{P}=0.14$ ), with 


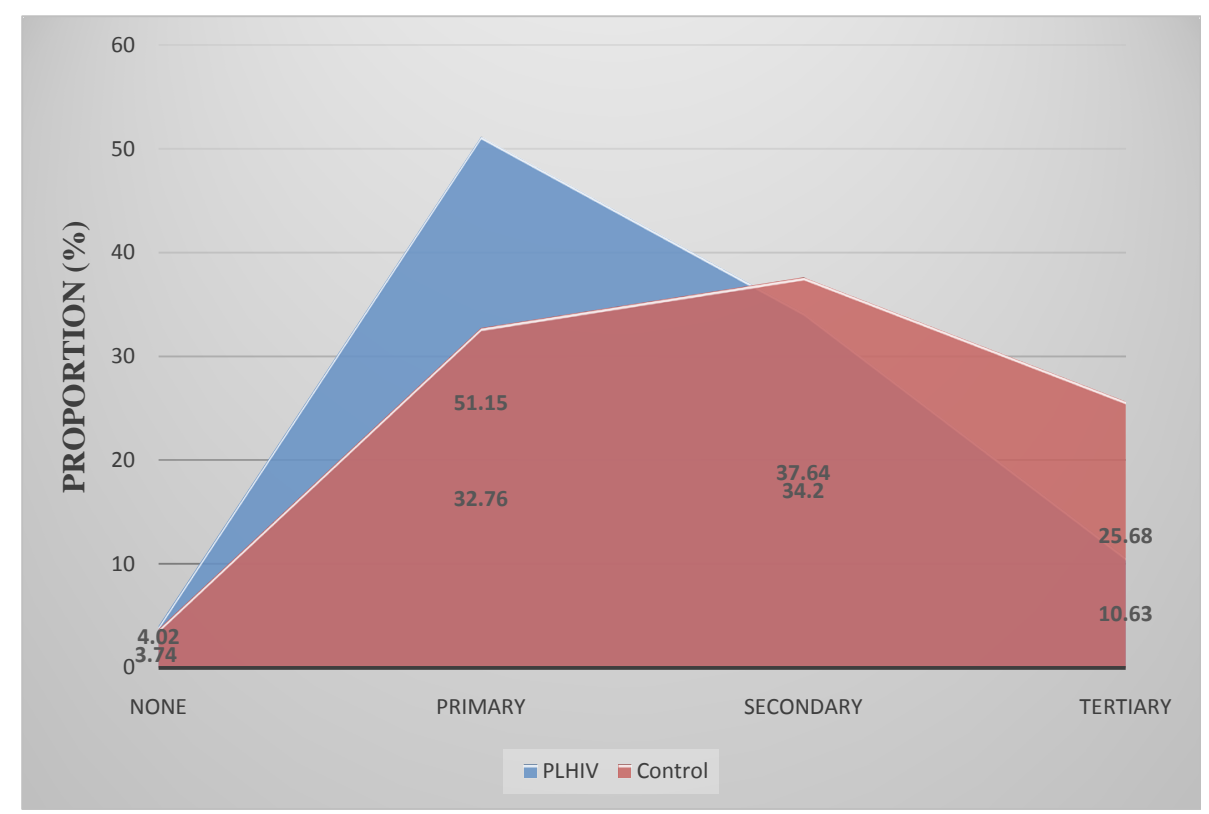

Figure 1. Educational levels of study participants.

very few of them involved in the public service $(17.77 \%$ vs. $26.86 \%$, OR $=0.99,95 \%$ CI: $0.42-2.34, \mathrm{P}=0.98)$ with a stable source of income (Figure 2). Overall there was a significant difference between the occupation of PLHIV and the control $\left(X^{2}=49.5721, \mathrm{P}<0.001\right)$.

\subsection{Sexual Characteristics}

PLHIV were more into polygamy (15.27\% vs. $12.47 \%$, OR $=1.51$, 95\% CI: $0.92-2.47, \mathrm{P}=0.11)$, meanwhile the control were more into monogamy ( $51.76 \%$ vs. $43.52 \%$, OR=1.03, 95\% CI: $0.72-1.49$, P $=0.93$ ). Relative to the control, a greater proportion of PLHIV were widows (13.26\% vs. $5.90 \%$, OR $=2.73,95 \%$ CI: $1.51-4.92$, $\mathrm{P}=0.001)$, divorced $(3.46 \%$ vs. $0.81 \%, \mathrm{OR}=5.23,95 \% \mathrm{CI}: 1.43-19.18, \mathrm{P}=0.007)$. Among those that were single and never married, the proportion of PLHIV 78 (22.48\%) was lower than that of the control 102 (27.64\%) (Figure 3).

Among individuals that were single and never married, PLHIV were significantly $\left(X^{2}=13.2084, \mathrm{P}=0.001\right)$ more sexually active than the control as a far greater proportion reported that they were into multi-partner sex (51.28\% vs. 28.43\%, OR = 4.55, 95\% CI: 1.94 - 10.69, P < 0.001) (Figure 4).

Out of 350 PLHIV, 225 (64.29\%) reported a history of STDs which was observed to be significantly higher than what was reported by the controls 171 (48.86\%) of the 350 (OR $=1.88,95 \%$ CI: $1.39-2.55, \mathrm{P}<0.001$ ). the most frequently reported STI was vaginal itches referred to as "Sugar-sugar" which pertains to either candidiasis or trichomoniasis (Figure 5).

\subsection{Risky Behaviour}

From this study, 280 (80\%, 95\% CI: 75.79 - 84.21) of the 350 PLHIV reported to have had sexual intercourse after being diagnosed. 127 (45.36\%, 95\% CI: 39.49 - 51.22) of the 280 patients who have had sexual intercourse reported using condoms. 148 (52.86\%, 95\% CI: 46.97 - 58.74) of the 280 patients admitted that their partner had been informed about their status meanwhile 132 (47.14\%, 95\% CI: 41.18 - 53.17) admitted that their partner was not aware of their status.

\section{Discussion}

The Human Immunodeficiency Virus (HIV) causes HIV/AIDS, a disease associated with progressive weakening of the human immune system making the individual more likely to get infections that usually does not occur in immunocompetent individuals [14]. As mentioned above, Cameroon with a prevalence of $5.5 \%$ is among the 


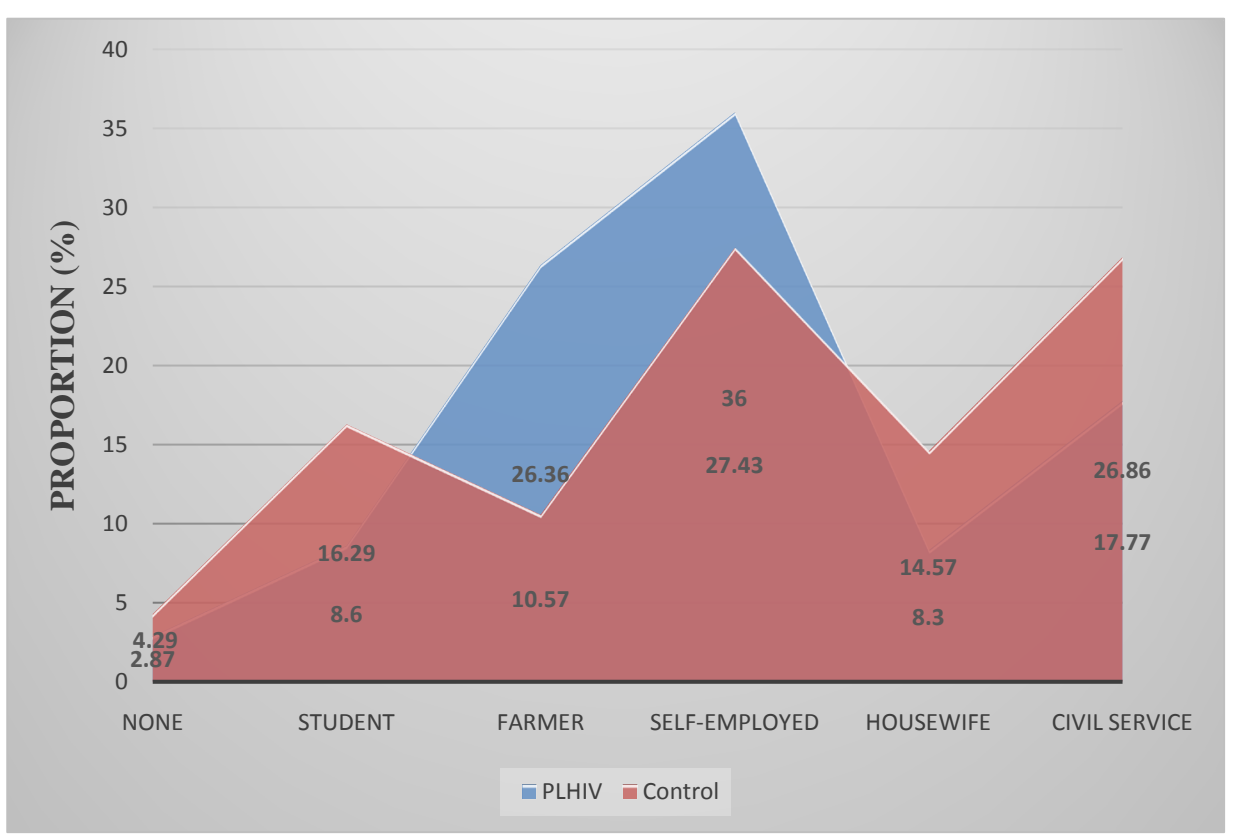

Figure 2. Occupational distribution of study participants.

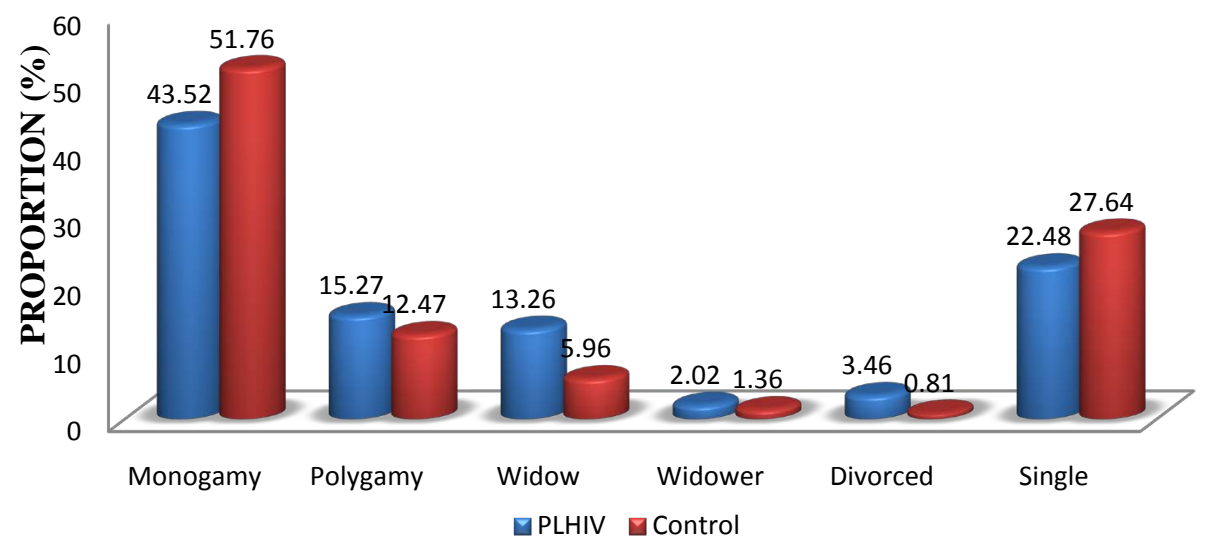

Figure 3. Sexual characteristics of study participants.

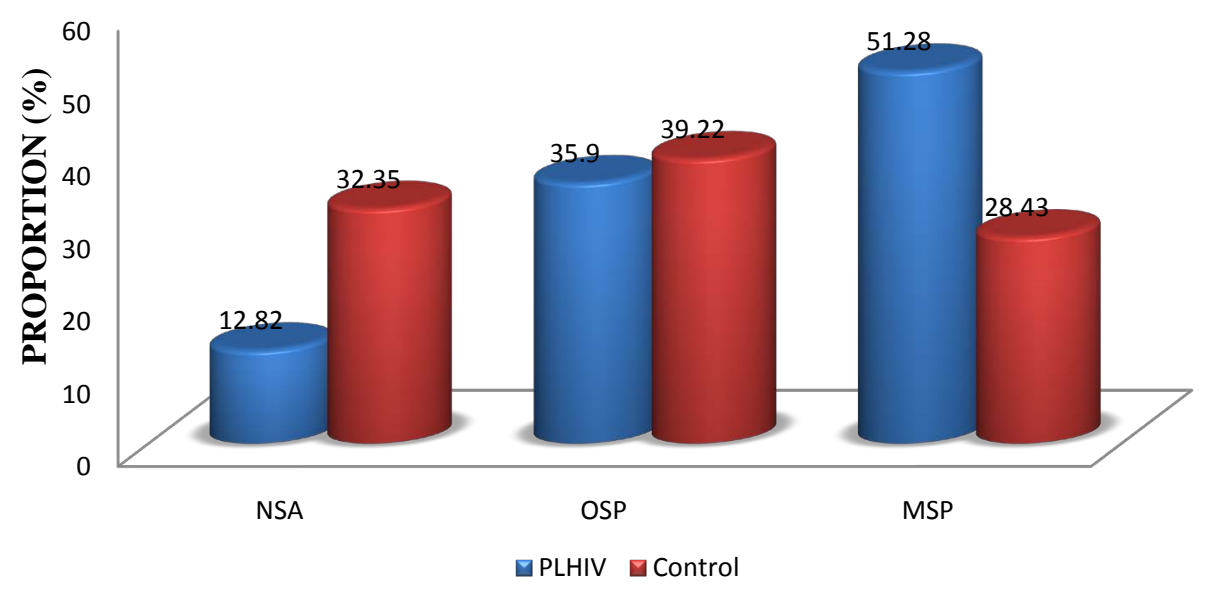

Figure 4. Sexual activity among participants that were never married (NSA = No Sexual Activity, OSP = One Sexual Partner, MSP = Multiple Sexual Partner). 


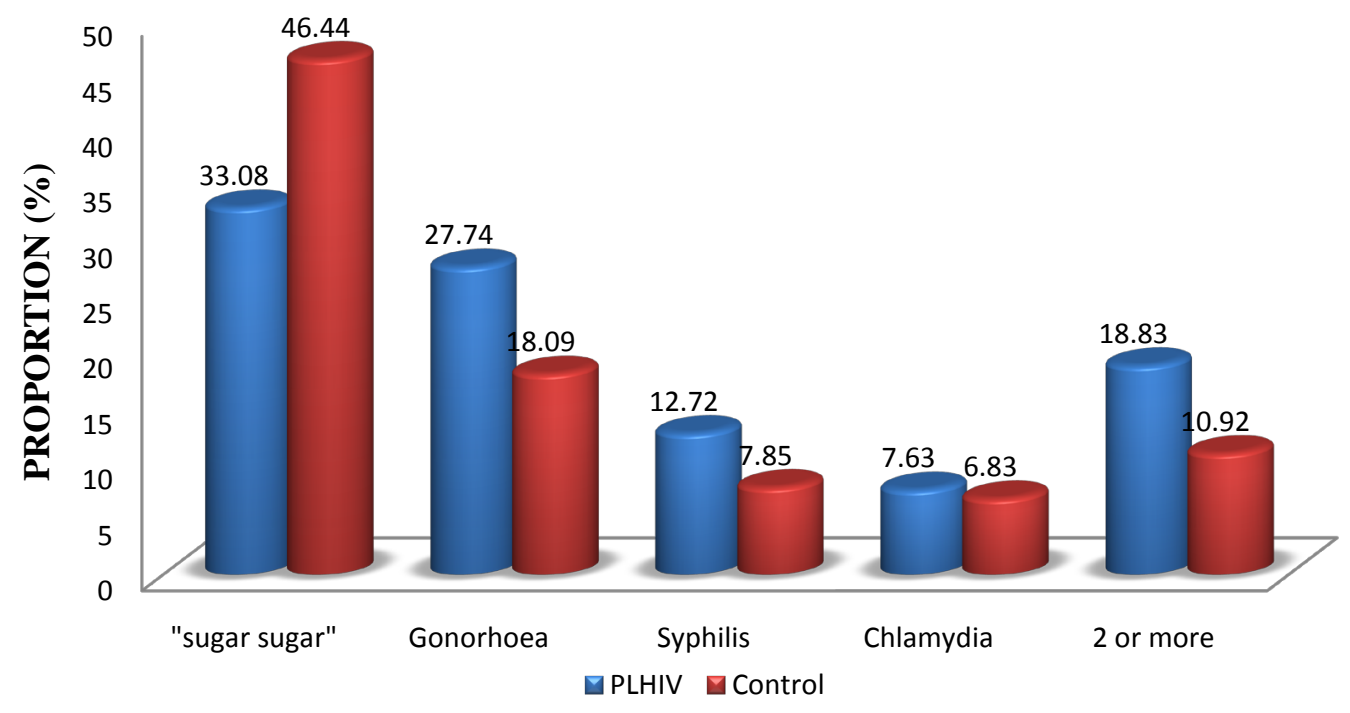

Figure 5. History of STIs in the study population ("sugar-sugar" pertains to vagina itches which may be due to candidiasis or trichomoniasis).

highest in West and Central Africa [4]. The impact of HIV/AIDS in Cameroon is heavily felt in the economic sector where the disease is taking a heavy toll on the youths, and also the society where an increasing number of children are being orphaned by HIV/AIDS [15]. The Cameroon government in 1986 created the National AIDS Control Committee (NACC) to coordinate AIDS programs nationally. Some of its main strategic plans were to prevent mother to child transmission; prevent HIV transmission through blood; enhancement of access to treatment and care and the involvement of all stakeholder in the fight against HIV/AIDs [16]. Through this program, considerable achievements have been made evidence by the decreasing prevalence of the disease [5]. Yet the number of new cases and PLHIV is still on the rise in the country [5]. The contributing factors behind these numbers are not clearly understood.

We studied the characteristics and sexual risky behaviour of PLHIV relative to controls and observed that PLHIV were generally less educated $(\mathrm{P}<0.001)$. Most of them attained only primary education with just a few progressing to the secondary and tertiary levels. It was also observed that a majority of PLHIV were farmers or generally self-employed with no steady source of income contrary to the control who were more involved in the public service with a steady source of income. Looking at the mean ages of the participants who were mainly youths, this is a reflection of the economic impact of HIV [17] as not only PLHIV will not be able to work and raise enough money, but will also require significant care and medical attention. These findings have implications in the control of the HIV which should be designed to target mostly the poor, underprivileged, and the less educated members of the population.

In this study, it was observed that PLHIV were more into polygamy meanwhile the control were more into monogamy. Among participants that were once married, a majority of PLHIV were divorced or widows. These are some of the factors that push PLHIV to engage into risky sexual practices as they search for new partners. Among individuals that were single and never married, PLHIV were significantly $(P=0.001)$ more sexually active as a greater proportion reported being involved in multi-partner sex. A greater proportion of PLHIV also reported a history of STDs than the control $(\mathrm{P}<0.001)$. These findings are in support of studies that report that multi-partner sex and STDs are risk factors for infection with HIV [9] [18] [19].

In this study, 80\% of PLHIV reported to have had sexual intercourse after being diagnosed of HIV, with only a few reporting that they used condoms (41.78\%), and a good number of them reported that their partner was not aware of their HIV status (47.14\%). Poor condom usage among PLHIV has also been reported in Douala, Cameroon [20]. Poor condom usage has been known as one of the risk factors for HIV infection [19] not only to those without infection but also for the acquisition of another HIV strain (superinfection) in PLHIV [21]. For those who reported that their partner was aware of their status, it is likely that they were a married couple and were both infected meanwhile for those that reported that their sexual partner was not aware of their HIV status, it is likely that they were not married and is characteristic of people with multiple sexual partners. These prac- 
tices by PLHIV could be the driving force in the ever increasing number of new infections in the study area. Studies have shown that treating PLHIV with antiretrovirals reduces the risk of transmission 10 to 20 folds [22] and provides $96 \%$ protection of their partners [23]. This is good news to HIV control programs which to aim at increasing the coverage of antiretrovirals in addition to educating PLHIV on their sexual behaviour, all of which could play a significant role in reducing the number of new number of new infections.

\section{Conclusions}

In this study it was observed that PLHIV were significantly less educated, poor and underprivileged with no steady source of income. PLHIV were observed to indulge more into sexual risky behaviour such as polygamy, divorced, widows, practiced multi-partner sex and low usage of condoms that not only exposes them to acquisition of another HIV strain (superinfection) but leads to infection of their partners thereby driving the ever increasing numbers of new infections and PLHIV in the North West Region of Cameroon.

As recommendations, HIV control programs should be designed to target the poor and less educated members of the population as well as PLHIV. PLHIV should be educated on their moral standard and risky sexual behaviour that put themselves and others at risk of infection. Education of PLHIV will be more cost-effective if it is integrated within HIV treatment programs. Lastly coverage of antiretrovirals should be increased to include many more PLHIV in rural areas as it has been associated with reduced risk of transmitting the virus from PLHIV to their otherwise non-infected partner.

\section{Authors' Contribution}

KET conceived the study, participated in data collection, performed the analyses and interpretation, conducted the literature search and review, and wrote the first draft. TBDK participated in data collection, conducted the literature search and review, and wrote the first draft. NDS participated in data analysis, conducted the literature search and review, and critically revised the manuscript. NAL participated in data analysis, conducted literature search and review, and critically revised the manuscript. All authors read and approved the final manuscript.

\section{References}

[1] UNAIDS (2013) Global Report: UNAIDS Report on the Global AIDS Epidemic 2013.WHO, Geneva, Switzerland. http://www.unaids.org/en/media/unaids/contentassets/documents/epidemiology/2013/gr2013/UNAIDS_Global_Report 2013_en.pdf

[2] Kallings, L.O. (2008) The First Postmodern Pandemic: 25 Years of HIV/AIDS. Journal of Internal Medicine, 263, 218-243. http://dx.doi.org/10.1111/j.1365-2796.2007.01910.x

[3] UNAIDS (2012) Global Report: UNAIDS Report on the Global AIDS Epidemic 2012. Geneva, Switzerland. http://www.unaids.org/en/media/unaids/contentassets/documents/epidemiology/2012/gr2012/20121120_UNAIDS_Glo bal_Report_2012_with_annexes_en.pdf

[4] UNAIDS/WHO (2004) Cameroon: Epidemiological Fact Sheet on HIV/AIDS and Sexually Transmitted Infections_-2004 Update. Geneva, Switzerland. http://data.unaids.org/publications/fact-sheets01/cameroon_en.pdf

[5] National AIDS Control Committee (2010) The Impact of HIV and AIDS in Cameroon through 2020. http://www.healthpolicyinitiative.com/Publications/Documents/1250_1_Cameroon_EN_Singles_Reduced_acc.pdf

[6] William, N.R. and Markowitz, S.B. (2007) Environmental and Occupational Medicine. 4th Edition, Wolters Kluwer/Lippincott Williams \& Wilkins, Philadelphia, 745.

[7] Boily, M.C., Baggaley, R.F., Wang, L., et al. (2009) Heterosexual Risk of HIV-1 Infection per Sexual Act: Systematic Review and Meta-Analysis of Observational Studies. The Lancet Infectious Diseases, 9, 118-129. http://dx.doi.org/10.1016/S1473-3099(09)70021-0

[8] Beyrer, C., Baral, S.D., van Griensven, F., et al. (2012) Global Epidemiology of HIV Infection in Men Who Have Sex with Men. Lancet, 380, 367-377. http://dx.doi.org/10.1016/S0140-6736(12)60821-6

[9] Ng, B.E., Butler, L.M., Horvath, T. and Rutherford, G.W. (2011) Population-Based Biomedical Sexually Transmitted Infection Control Interventions for Reducing HIV Infection. In: Butler, L.M., Ed., Cochrane Database of Systematic Reviews, online, 3.

[10] Kerrigan, D., Wirtz, A., Semini, I., et al. (2012) The Global HIV Epidemics among Sex Workers. World Bank Publications, Washington DC, 1.

[11] Aral, S.O., Fenton, K.A. and Lipshutz, J.A. (2013) The New Public Health and STD/HIV Prevention: Personal, Public 
and Health Systems Approaches. Springer, 120. http://dx.doi.org/10.1007/978-1-4614-4526-5

[12] World Gazetteer (2013) Cameroon: Largest Cities and Towns and Statistics of Their Population. http://archive.today/lRcpV

[13] Kwenti, E.T., Njouom, R., Njunda, L.A. and Kamga, H.L.F. (2011) Comparison of an Immunochromatographic Rapid Strip Test, ELISA and PCR in the Diagnosis of Hepatitis C in HIV Patients in Hospital Settings in Cameroon. Clinical Medicine and Diagnostics, 1, 21-27. http://dx.doi.org/10.5923/j.cmd.20110101.04

[14] Sepkowitz, K.A. (2001) AIDS-The First 20 Years. The New England Journal of Medicine, 344, 1764-1772. http://dx.doi.org/10.1056/NEJM200106073442306

[15] Nsagha, D.S., Bissek, A.C.Z.K., Nsagha, S.M., et al. (2012). The Burden of Orphans and Vulnerable Children Due to HIV/AIDS in Cameroon. The Open AIDS Journal, 6, 245-258. http://dx.doi.org/10.2174/1874613601206010245

[16] Mbanya, D., Sama, M. and Tchounwou, P. (2008). Current Status of HIV/AIDS in Cameroon: How Effective Are Control Strategies? International Journal of Environment Research and Public Health, 5, 378-383. http://dx.doi.org/10.3390/ijerph5050378

[17] Mandell, G.L., Bennett, J.E. and Dolan, R. (2010) Principles and Practice of Infectious Diseases.

[18] Chen, L., Jha, P., Stirling, B., et al. (2007) Sexual Risk Factors for HIV Infection in Early and Advanced HIV Epidemics in Sub-Saharan Africa: Systematic Overview of 68 Epidemiological Studies. PLoS ONE, 2, e1001. http://dx.doi.org/10.1371/journal.pone.0001001

[19] US President's Emergency Plan for AIDS Relief (PEPFAR) (2012) Cameroon Operational Plan Report FY 2011, 1-54.

[20] Essomba1, N., Kollo, B., Fouda, A.B., et al. (2013) Sexual Risk Behaviours among Patients Living with HIV/AIDS in Douala in 2012. Health Sciences and Research, 14, 36-43.

[21] Van der Kuyl, A.C. and Cornelissen, M. (2007) Identifying HIV-1 Dual Infections. Retrovirology, 4, 67. http://dx.doi.org/10.1186/1742-4690-4-67

[22] Chou, R., Selph, S., Dana, T., et al. (2012) Screening for HIV: Systematic Review to Update the 2005 US Preventive Services Task Force Recommendation. Annals of Internal Medicine, 157, 706-718. http://dx.doi.org/10.7326/0003-4819-157-10-201211200-00007

[23] Anglemyer, A., Rutherford, G.W., Baggaley, R.C., Egger, M. and Siegfried, N. (2011) Antiretroviral Therapy for Prevention of HIV Transmission in HIV-Discordant Couples. In: Rutherford, G.W., Ed., Cochrane Database of Systematic Reviews, John Wiley \& Sons, Ltd., The Cochrane Library, 8.

\section{List of Abbreviations}

HIV: Human Immunodeficiency Virus

AIDS: Acquired Immunodeficiency Syndrome

PLHIV: People Living with HIV

STD: Sexually Transmitted Diseases

NACC: Cameroon's National AIDS Control 
Scientific Research Publishing (SCIRP) is one of the largest Open Access journal publishers. It is currently publishing more than 200 open access, online, peer-reviewed journals covering a wide range of academic disciplines. SCIRP serves the worldwide academic communities and contributes to the progress and application of science with its publication.

Other selected journals from SCIRP are listed as below. Submit your manuscript to us via either submit@scirp.org or Online Submission Portal.
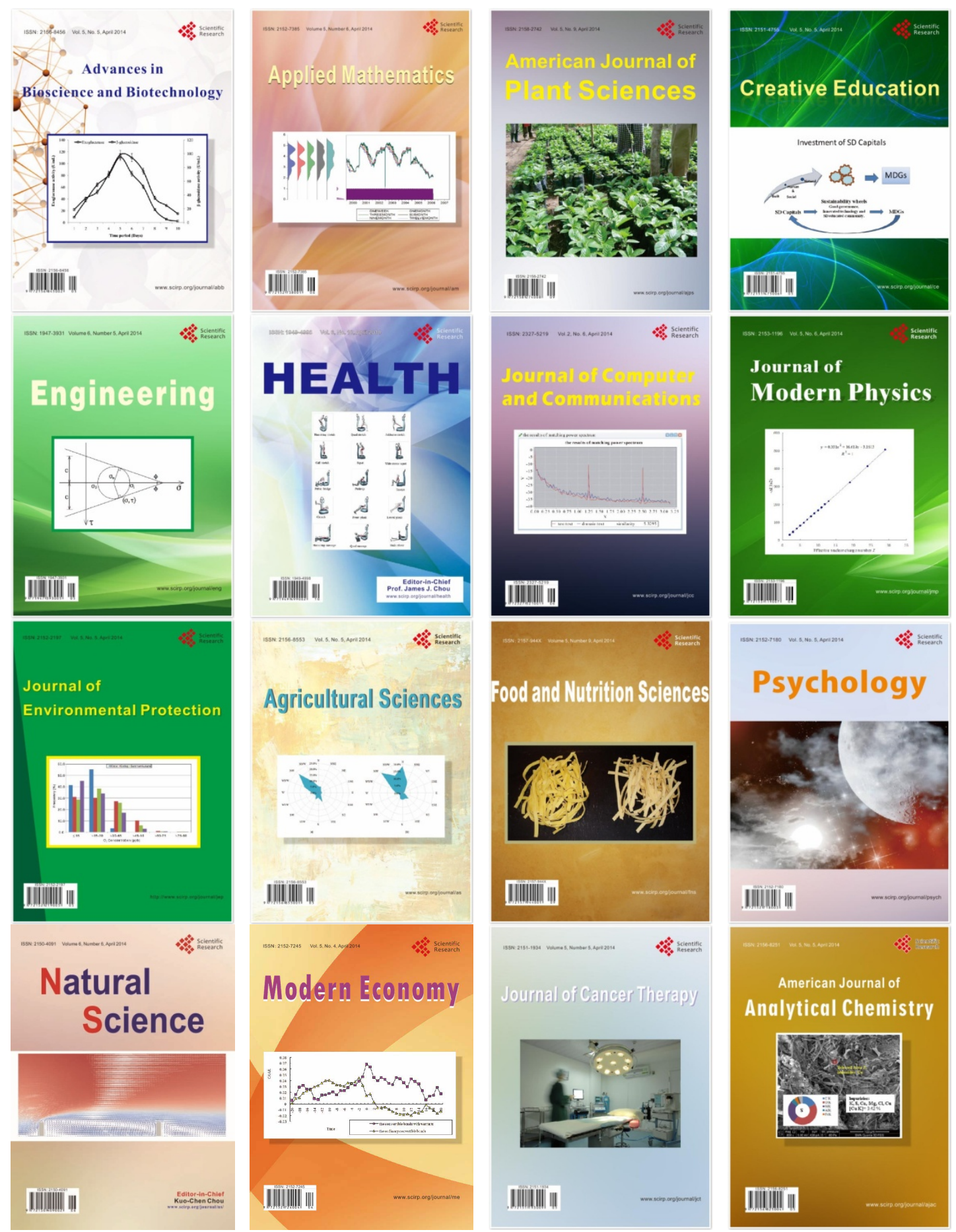